\title{
Smart Optical Assist for the Visually Impaired Person
}

\author{
H.M Dewruwani Nimthara", T.S.K.B.Kelegama**, S.V.S Gunasekara** \\ * Department of Information Technology, Cinec Campus \\ ${ }^{* *}$ University of wolverhampton, UK \\ DOI: 10.29322/IJSRP.11.09.2021.p11758 \\ http://dx.doi.org/10.29322/IJSRP.11.09.2021.p11758
}

\begin{abstract}
People who are completely blind or have limited vision typically struggle to navigate unfamiliar situations by themselves. It might be tough to travel or even stroll through a busy street. As a result, many persons with impaired vision seek the help of a sighted friend or relative. It is also harder for them to maintain track of their daily routines, and the typical blind walking stick has its own set of problems and restrictions. It is of little use to these members of our society. This study was inspired by the inability of physically disabled persons to walk, and therefore attempted to make their daily lives as pleasant and trouble-free as possible. By combining several sensors with the Raspberry Pi, proposed system is created a smart glass. The functionality and working principle of smart glasses, and the variety of activities it may perform, are presented in this article. This work is unique in that it processes data from the device to give a better navigation and day-to-day activity solution.
\end{abstract}

Index Terms- object detection, face recognition, voice processing, OpenCV, Raspberry Pi

\section{INTRODUCTION}

Over the last few decades, the number of visually impaired persons has increased across all age categories. According to the WHO, there are 285 million individuals worldwide who are visually impaired, 39 million of whom are blind, and 246 million who have poor vision [1]. Losing one's sight or eyesight makes it harder to communicate with people and to expand one's knowledge and experience. The visually impaired are often placed in separate courses and treated differently, which has resulted in them being isolated from society and prohibiting them from engaging with others and obtaining the same amount of information as a regular person.

On the other hand, according to the EnableMart online website, new aids and technologies created for the visually impaired are deemed costly, with prices ranging from $\$ 200$ to $\$ 3000$ or more. The cost is determined by the work that the device or program is doing, with the majority of them being built for single-task use. Considering the above, visually impaired persons are the focus of numerous academics who are attempting to make their life easier in a variety of ways.

This study introduces a novel spectacles that are designed to assist visually impaired persons in broadening their horizons by describing live situations in front of them. The scenarios are categorized into a mode format that users may alter as needed, such as speech processing, object detection, and facial recognition. 


\section{IDENTIFY, RESEARCH AND COLLECT IDEA}

\section{A. Quantitative Research}

Quantitative data was gathered for this research using existing data by analyzing research publications based on blind people. Further, to identify the best tools and techniques, used some publications and other internet resources. Those studied resources are [18] [19] [20] [21] [22] [23]. These resources describe the best tools to carry out the research with current technology.

\section{B. Qualitative Research}

Interviews with patients, parents, and guardians from various family background were used to collect qualitative data, and the predicted device was assessed according to the patient, parent, and guardian. The study of each research's benefits and drawbacks aided in improving the predicted device's performance.

\section{Experimental Research}

The system consists of two circuits. One circuit for the Raspberry pi 4 and the other one is for Arduino.

Raspberry pi 4 used to monitor the distance between patient and object, to identify the face and objects. The Raspberry pi 4 connected with laptop using Ethernet cable. Installed Raspbian OS to the SD card and create SSH folder in SD card. Then power on the Raspberry $\mathrm{Pi}$. OpenCv is the suitable software for image processing. Therefor Installed OpenCV software and OpenCV libraries which use imageprocessing and installed eSpeak to voice output. Create wire connections after completing the installations.

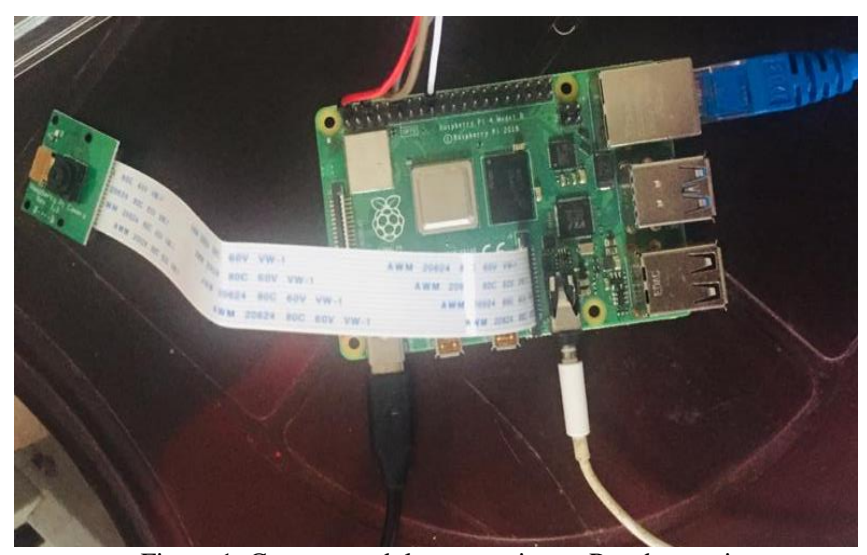

Figure 1: Camera module connection to Raspberry pi

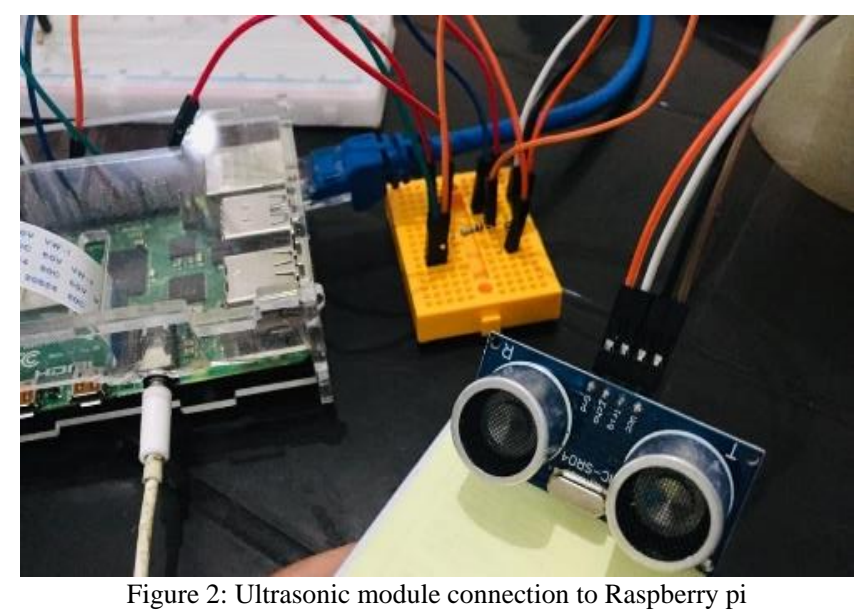

TABLE 1: RASPBERRY PI MODULE AND POWER CONNECTION

\begin{tabular}{|l|l|c|}
\hline Module & Raspberry pi & Power \\
\hline Camera cable & Camera module port & \\
\hline Headset & Audio Jack & \\
\hline
\end{tabular}


Created the file named as "haarcascade_frontalface_default.xml" file created to train real-time dataset. Then created a file named "ssd_mobilenet_v3_large_coco_2020_01_14.pbtxt and "frozen_inference_graph.pb" which includes a trained data set to face recognition and objects detection.

Arduino is using to send a message to parent or guardian during any emergency situation by clicking on a button. Then created a connection between Arduino Uno board with limit switch and GSM module.

TABLE 2: ARDUINO UNO MODULE AND POWER CONNECTION

\begin{tabular}{|l|l|}
\hline Ultrasonic sensors & Raspberry pi \\
\hline Vcc Pin & 5v pin \\
\hline Trig Pin & 18 Pin \\
\hline Eco Pin & 24 Pin \\
\hline Ground Pin & Ground Pin \\
\hline
\end{tabular}

TABLE 3: ARDUINO CIRCUIT CONNECTION

\begin{tabular}{|c|c|c|c|}
\hline GSM & Adopter & Arduino Uno & Limit Switch \\
\hline Pin Vcc & + Side & - & - \\
\hline Pin Tx & - & 11 Pin & - \\
\hline Pin Rx & - & 12 Pin & - \\
\hline- &..- Side & Ground & - \\
\hline- & - & 5v Pin & Normally on \\
\hline- & - & 9 Pin & Common \\
\hline
\end{tabular}

By using android studio and firebase, implemented the mobile app for the parents and guardian to find the place of the blind person. Further, patient can send a message to the parent or guardian by clicking on the button in Arduino. 


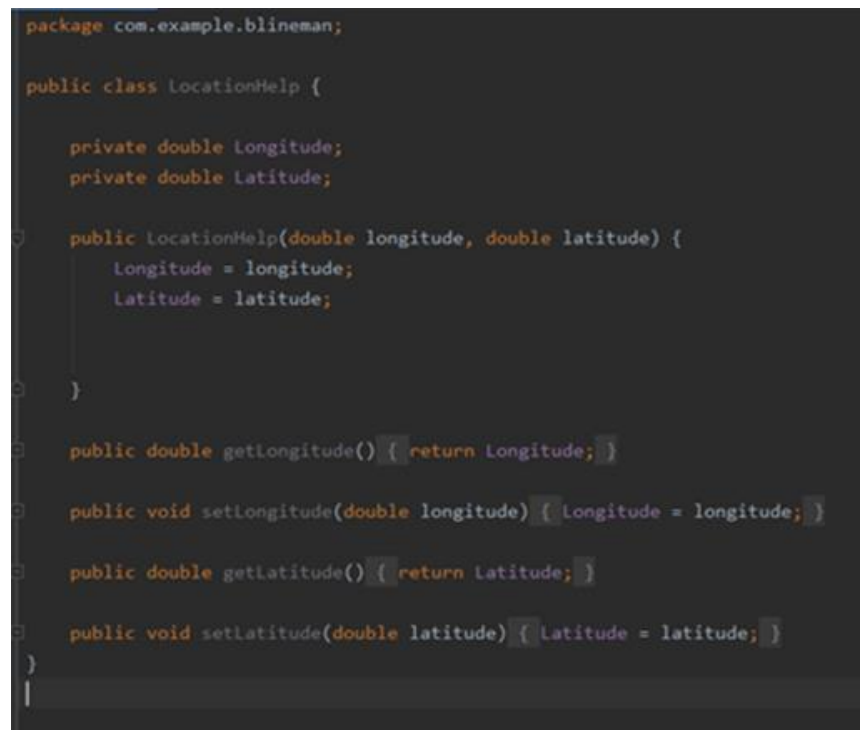

Figure 3: Get location details

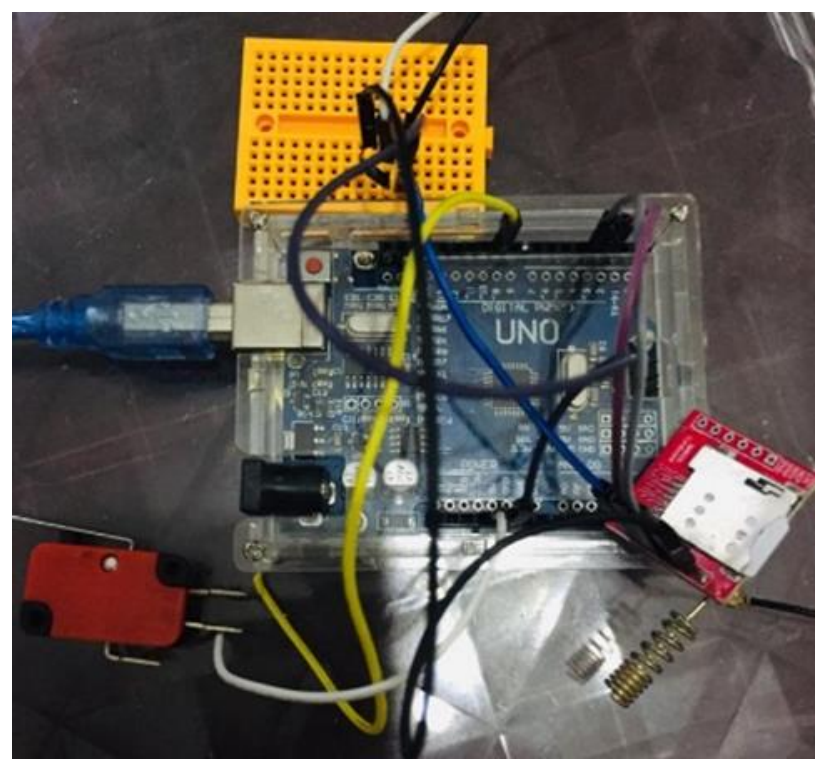

Figure 4: Connection between GSM Module, Arduino Uno board and Limit switch.

\section{WRITE DOWN YOUR STUDIES AND FINDINGS}

Using Raspberry pi 4, Camera module pi 3, Ultrasonic sensors and headphones this system developed for object recognize, facial recognize and distance measuring.

\section{Object detecting}

Raspberry Pi 3 camera identify the objects which is in front of the camera. Also Result provides a voice output. 


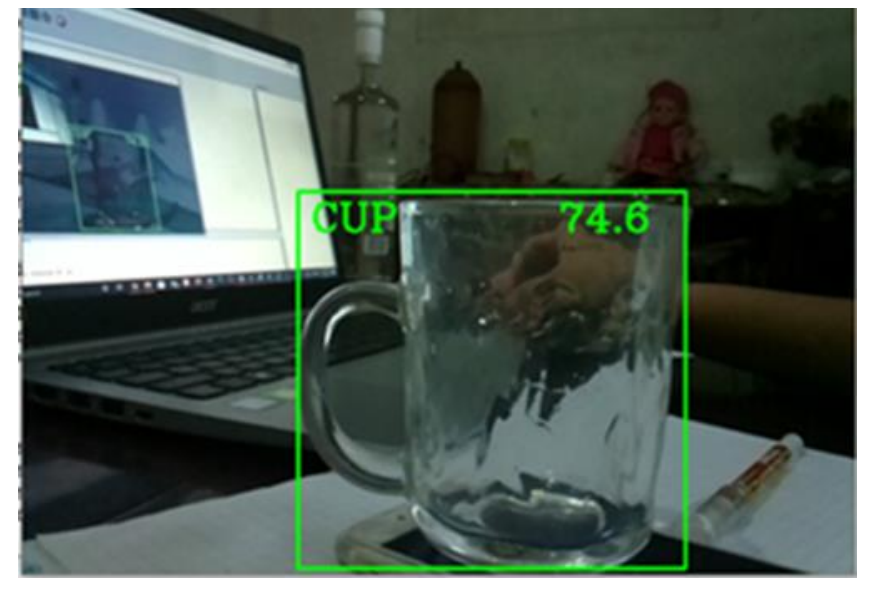

Figure 5: display the result of recognized object

\section{Facial recognize}

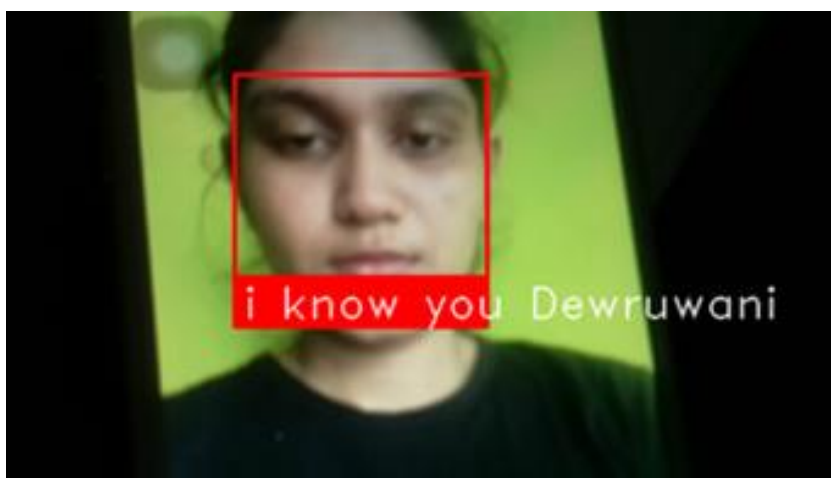

Figure 6: Identify as known person

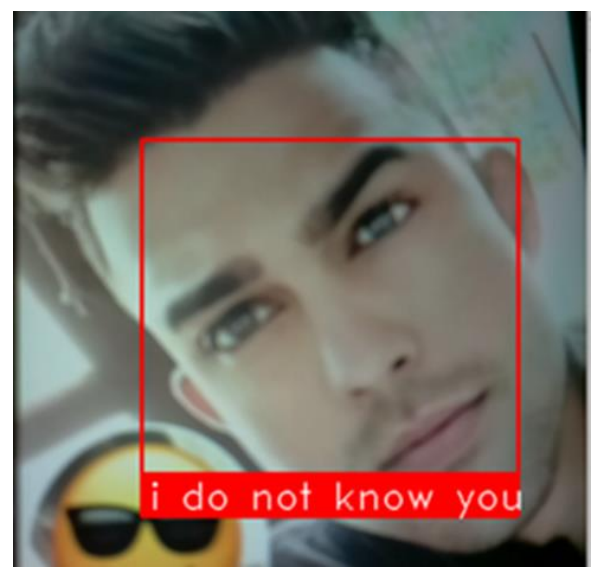

Figure 7: Identified as unknown person

Raspberry pi3 camera module able to identify person in front of the pi 3 camera and identifies whether the person is known or unknown. Also Result will provide voice output.

\section{Distance Measuring}

Ultrasonic sensor measures the distance between each object. When measurement of object less than $18 \mathrm{~cm}$ then system will provide voice output as "Obstacle nearby 'the Distance" ". 


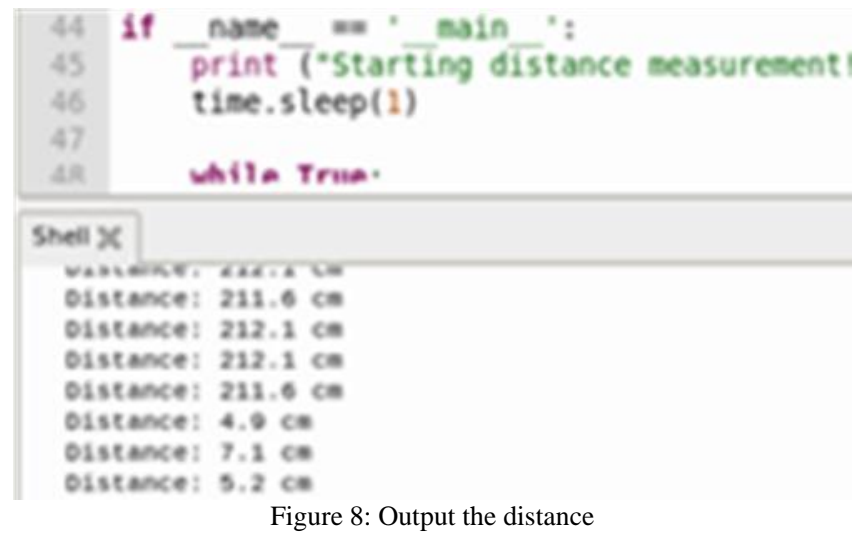

\section{Send emergency message}

When the blind patient clicks on the limit switch GSM Module, it sends a message to the related guardian. That will help to the blind person to respond in emergency situations.

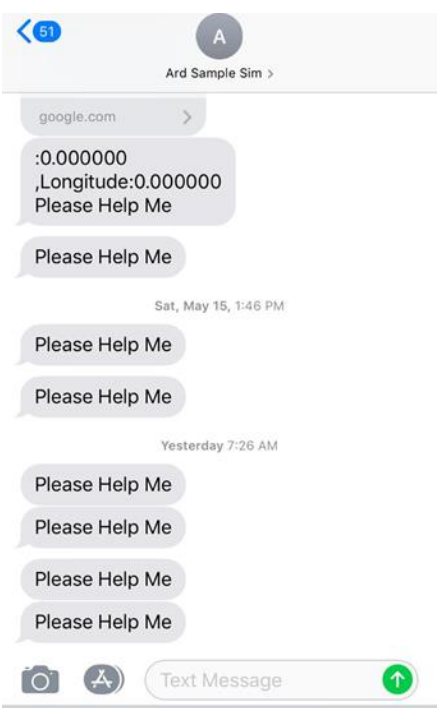

Figure 9: Sent messages

\section{Tracking Application}

The Application developed using Java, Google API and Android studio send the location of blind person to the parent or guardian. 


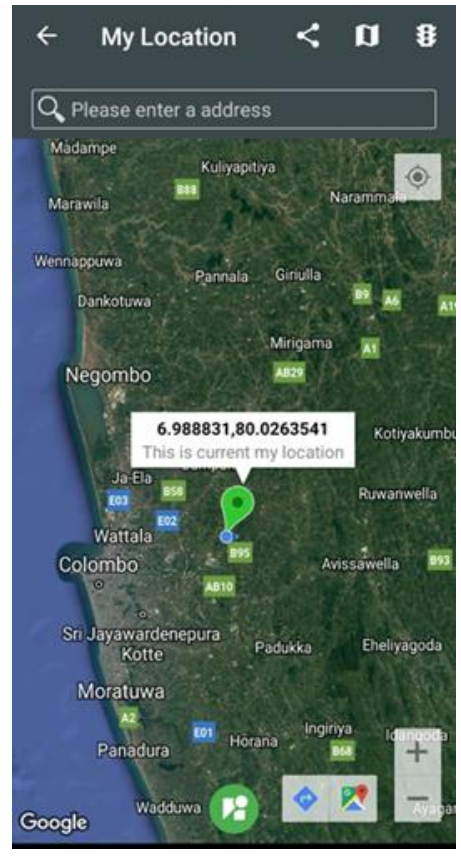

Figure 10: Shows location

\section{Prototype model}

The smart optical assist project is implemented with the use of perfect software solution and perfect module, and it reduces difficulties which are faced by the blind persons and giving them more independence in their day-to-day life. Therefore, this proposed system is the best solution for visually impaired people. 


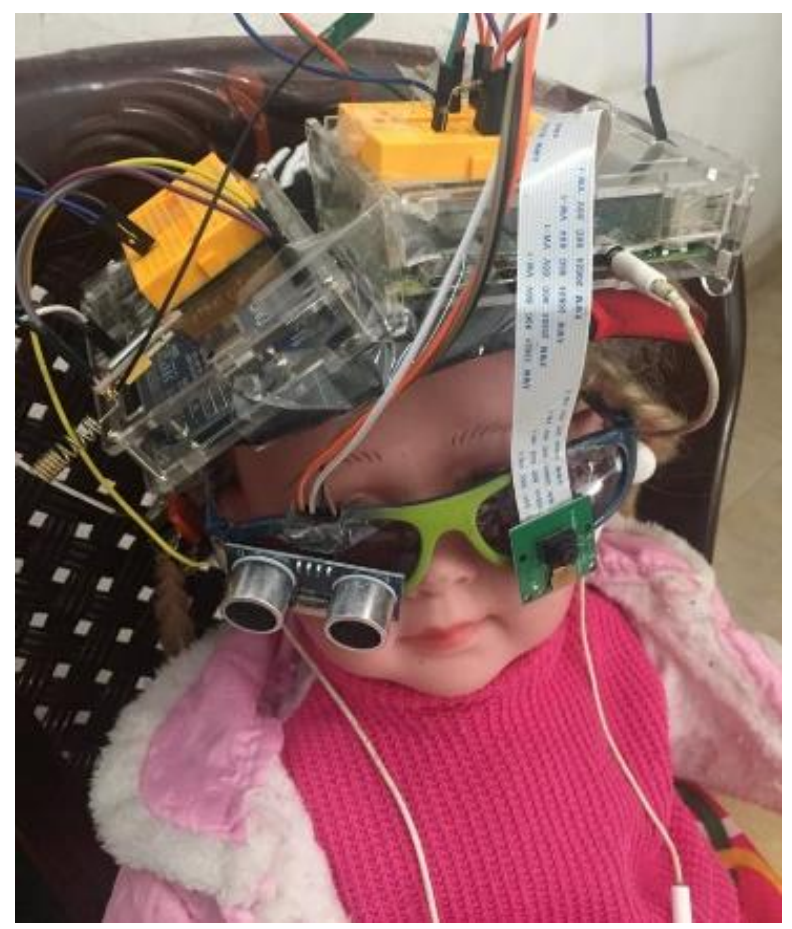

Figure 11: Prototype design of the system

\section{IMPROVEMENT AS PER REVIEWER COMMENTS}

More optimization functions should be introduced in the future, and user testing data and comments should be provided for greater development. As a consequence of the experiment findings, it has been determined that camera quality is a critical component; thus, a better camera should be added to the system as a recommendation to increase the accuracy of the results. It may also be used with a neo PI camera to take photos in low-light conditions.

Furthermore, by implementing text- reading technology and a waterproof design, blind people will be able to read books and use this device underwater and on rainy days.

\section{CONCLUSION}

People who are visually impaired are either completely blind or have very low vision that is legally defined as blindness. The number of visually impaired persons has risen in recent decades, and the challenges they confront in daily life are getting increasingly severe as a result of new technology, population growth, buildings, , and other factors. This initiative aims to assist these individuals in expanding their independence by providing them with an audio description of live situations provided through an earphone. The main software package for the project is OpenCV, and the single board computer Raspberry Pi 4 serves as the platform.

The project also makes use of a Camera Module Pi 3 to capture real-time objects and an earphone to speak the descriptions out loud. Also, it is developed an Android application to track the blind person using Android studio platform. The project is being conducted 
with a focus on cost effectiveness, which is maintained as low as feasible; as seen in the cost analysis table above, the final prototype only cost $\$ 105$.

\section{ACKNOWLEDGMENT}

I would like to convey my heartfelt appreciation to everyone who guided me and provided information to assist me finish my project during the course.

First and foremost, I want to express my gratitude to the supervisors and lecturers at the Department of Information Technology, CINEC Campus, Malabe, Sri Lanka, for their continual monitoring and encouragement. I'd also want to express my gratitude to Ms. Thamali Kelagama for her support and advice during the project. Finally, I want to express my gratitude to my family members as well as everyone else who contributed to the project's completion.

\section{REFERENCES}

[1] W. H. Organization, "WHO | Visual impairment and blindness," World Health Organization," 7 Apirl 1948. [Online]. Available: http://www.who.int/mediacentre/factsheets/fs282/en/. [Accessed 15 April 2021].

[2] A. A. T. A. K. J. M. S. A. Mohd Helmy Abd Wahab, "Smart Cane: Assistive Cane for Visually-impaired People," International Journal of Computer Science Issues (IJCSI ), vol. VIII, no. 4, pp. 21-27, 2011.

[3] H. N. .. J, "Deviance : T he Symboli Interactionist Approach-The Making of Blind Men," vol. 24, pp. 236-240, 1999.

[4] P. S. Jake V. Bouvrie, "Visual object concept discovery: Observations in congenitally blind children, and a computational approach," ELSEVIER, pp. 2218-2233, 2007.

[5] K.-T. S. Charles C. Chang, "Ultrasonic sensor data integration and its application to environment perception," Journal of Robotic Systems, vol. 1, pp. 3-5, 1996.

[6] J. S. E. P. C. W. a. M. R. A. Ganz, "Quantitative and Qualitative Evaluation of PERCEPT Indoor Navigation System for Visually Impaired Users," Engineering in Medicine and Biology Society (EMBC), 2012-Sept.

[7] D. Jain, "Path-Guided Indoor Navigation for the Visually Impaired," ACM SIGACCESS conference on Computers \& accessibility, 2014.

[8] R. J. a. S. A. Ali, "Exploring the Potential of Eyewear-Based Wearable Display Devices for Use by the Visually Impaired," International Conference on User Science and Engineering, pp. 2-5, 2014.

[9] S. A. a. M. Y. I. Anam, "'Expression: A Dyadic Conversation Aid using Google Glass for People who are Blind or Visually Impaired," in International Conference on Mobile Computing, Applications and Services, Austin, TX, Nov. 2014.

[10] R. J. a. S. A. Ali, "Exploring the Potential of Eyewear-Based Wearable Display Devices for Use by the Visually Impaired," in International Conference on User Science and Engineering, 2014.

[11] D. Z. J. S. Pablo Monje Vera, "A smartphone-based virtual white cane," in Pattern Analysis and Applications, August 2014.

[12] K. C. ,. E. H. John-Ross Rizzo, "A new primary mobility tool for the visually impaired: A white cane-adaptive mobility device hybrid," Assist Technol, vol. 5, no. 30, pp. 219-225, 2017 May 16.

[13] K. Y. W. P. G. R. S. S. Pyun R, "Advanced Augmented White Cane with obstacle height and distance feedback," IEEE Int Conf Rehabil Robot, June, 2013.

[14] C. R. N. A. T. Z. Gao Y, "Wearable Virtual White Cane Network for navigating people with visual impairment," Proc Inst Mech Eng H, vol. 229, no. 9, pp. 681-668, 2015 Sep.

[15] E. R. N. K. Kim DS, "Effect of cane length and swing arc width on drop-off and obstacle detection with the long cane.," $B r J V i s$ Impair, vol. 35, no. 3, pp. 217-231, 2017.

[16] P. S. M. Bujacz, "Sonification: Review of Auditory Display Solutions in Electronic Travel Aids for the Blind," Archives of Acoustics, vol. 41, no. 3, pp. 401-414, September 2016.

[17] I. L. L. T. F. B. Larisa Dunai, "Obstacle detectors for visually impaired people," in International Conference on Optimization of Electrical and Electronic Equipment (OPTIM), 2014.

[18] N. Heath, "ZDNet," 2 July 2019. [Online]. Available: https://www.zdnet.com/article/what-is-the-raspberry-pi-4-everything-youneed-to-know-about-the-tiny-low-cost-computer/. [Accessed 0401 2021].

[19] Red Hat Inc, "Opensource.com," 2021. [Online]. Available: https://opensource.com/resources/raspberry-pi. [Accessed 2203 2021]. 
[20] D. Jost, "Fierce Electronics," 07 October 2012. [Online]. Available: https://www.fierceelectronics.com/sensors/what-ultrasonicsensor. [Accessed 05 February 2021].

[21] Elprocus, "Elprocus Electronics," 2021. [Online]. Available: https://www.elprocus.com/what-is-arduino-uno-r3-pin-diagramspecification-and-applications/. [Accessed 08 January 2021].

\section{AUTHORS}

First Author - H.M Dewruwani Nimthara, research holder, Cinec Campus and nimthara.rbv@gmail.com.

Second Author - T.S.K.B.Kelegama, Lecture, Cinec Campus and Thamali.Kelegama@ cinec.edu.

Third Author - S.V.S Gunasekara, Lecture, Cinec Campus (if any) and sachini.vindya @ cinec.edu. 